\title{
EDUCAÇÃO AMBIENTAL E OS \\ DESAFIOS PARA IMPLEMENTAÇÃO DE POLÍTICAS PÚBLICAS EM MATO GROSSO DO SUL
}

\author{
Simone Mamede ${ }^{1}$ \\ Maristela Benites ${ }^{1}{ }^{2}$ \\ José Flávio Rodrigues Siqueira ${ }^{3}$ \\ Marcos Vinícius Campelo Junior ${ }^{4}$
}

Resumo: O estado de Mato Grosso do Sul (MS) traz em sua história a ideia do desenvolvimentismo fundamentado pelo setor do agronegócio e pela política neoliberal estabelecida, causa de fortes embates com educadores ambientais no campo das políticas públicas socioambientais. Diante disso, o presente trabalho buscou apresentar o histórico e os principais desafios para implementação das políticas públicas em Educação Ambiental no estado de MS. Apresentamos eventos históricos da Educação Ambiental, publicações de livros de Educação Ambiental, redes de Educação Ambiental; Educação Ambiental no contexto escolar e os desafios para consolidação das políticas públicas de Educação Ambiental. Revelou-se que os educadores ambientais e suas redes tiveram e têm papel preponderante nas diversas atividades, ações e propostas educativas relacionadas às políticas públicas de MS para construção de uma sociedade mais justa, igualitária e de respeito ao ambiente.

Palavras-chave: Mato Grosso do Sul; Redes; Educadores Ambientais; Políticas Públicas.

\footnotetext{
${ }^{1}$ Instituto Mamede de Pesquisa Ambiental e Ecoturismo. E-mail: simone.mamede1@gmail.com. Link para o Lattes: http://lattes.cnpq.br/7260694164560471

2 Universidade Federal de Mato Grosso do Sul,, Campus Campo Grande-MS.

E-mail: maris.benites@gmail.com. Link para o Lattes: http://lattes.cnpq.br/7006699867493716

${ }_{3}^{3}$ Universidade Federal de Mato Grosso do Sul, Campus Campo Grande-MS.

E-mail: siqueirajfr@gmail.com. Link para o Lattes: http://lattes.cnpq.br/7968205214958350

4 Universidade Federal de Mato Grosso do Sul, Campus Campo Grande-MS.

E-mail: campelogeografia@gmail.com. Link para o Lattes: http://lattes.cnpq.br/5608728963095314
} 
Abstract: The state of Mato Grosso do Sul (MS, Brazil) has in its history the idea of developmentalism based on the agribusiness sector and the established neoliberal policy, which causes strong clashes with environmental educators in the field of socio-environmental public policies. In view of this, the present work sought to present the history and the main challenges for the implementation of public policies in environmental education in the MS state. We present historical events of environmental education, publications of environmental education books, environmental education networks; environmental education in the school context and the challenges for consolidating public policies on environmental education. It was revealed that environmental educators and their networks had and have a preponderant role in the various activities, actions, and educational proposals related to public policies in MS to build a more just, equalitary and respectful society with the environment.

Key-words: Mato Grosso do Sul; Networks; Environmental Educators; Public Policy.

\section{Introdução}

Mato Grosso do Sul é um estado ainda jovem, originado da divisão do estado do Mato Grosso em 1977. Desde sua origem tem buscado construir e consolidar políticas públicas em Educação Ambiental, cujas estratégias vislumbram ações participativas, no entanto, nem sempre assertivas. Isto se descreve não pela vontade da sociedade civil, mas, por se tratar de ato político, as instâncias de governança representadas pelo setor governamental, por vezes, esbarram em dificuldades nesse exercício e na sua implantação. Com frequência, tais entraves se dão pela ausência do processo dialógico entre Estado e sociedade civil e necessitam de estudos e intervenções com enfoques pluralistas e abrangentes, conforme sugerem Sorrentino et al. (2005).

Apesar do pouco tempo decorrido da criação do estado, as formas de produção e consumo hegemônicos não diferem de outros territórios marcados pela desigualdade social e presença de extensas áreas privadas, cuja pressão sobre os bens naturais é a principal forma de exploração econômica. Aqui se revela a indissociabilidade entre o universal e o singular, onde as expressões do singular constituem a realização do universal (ALVES, 2003). Portanto, essa breve contextualização torna-se importante para a compreensão da historiografia e desdobramentos da Educação Ambiental no Mato Grosso do Sul.

\section{Eventos históricos da Educação Ambiental no Mato Grosso do Sul}

A Educação Ambiental iniciou sua trajetória no estado da mesma forma que se praticava em outros lugares da nação e do mundo, constituindo-se como principal linha de ação para o enfrentamento da degradação dos bens naturais. Nesse sentido, ações conservadoras e tradicionais como conscientização ambiental e recuperação de áreas degradadas protagonizaram 
as iniciativas, com pouco estímulo ao pensamento crítico e transformação de atitudes que transcendessem o contexto físico da reparação dos danos ambientais, mas considerassem o tecido socioambiental como substrato para as ações e consequente êxito. No entanto, com o amadurecimento da própria Educação Ambiental novas epistemologias foram agregadas e novos saberes integrados, embora não se tenham extinguido formas mais conservadoras e pontuais do exercício da EA.

Ações em Educação Ambiental no estado do Mato Grosso do Sul datam da sua formação no final dos anos 70 e início da década de 80 . Nos anos 80 destaca-se o Congresso Internacional sobre a Conservação do Pantanal - INTERPAN, evento intitulado "O futuro que a gente faz", realizado pelo estado do Mato Grosso do Sul com apoio da ong World Wildlife Fund (WWF). O evento congregou os temas Educação Ambiental, cultura, socioeconomia, recuperação de áreas degradadas, dentre outros assuntos relacionados. No diálogo, a proposta aquiescente se referia ao planejamento adequado apoiado em uma política de integração entre planalto e planície pantaneira que permitisse o desenvolvimento socioeconômico aliado à conservação ambiental.

Ações como do Plano de Conservação da Bacia do Alto Paraguai PCBAP realizado entre 1992 e 1997, visaram caracterizar o Pantanal e diagnosticar problemas socioambientais com subsídios também para políticas públicas em Educação Ambiental. Assim, ocorreu o Projeto Global Environmental Facility (GEF) Pantanal - Alto Paraguai, financiado pelo Fundo Mundial para o Meio Ambiente e desenvolvido entre 1997 e 2003. As ações facilitaram a consolidação de espaços de diálogos, a criação de consórcios, grupos de trabalhos, colegiados e comitês de bacias hidrográficas contribuindo na construção e fortalecimento de instrumentos para a Educação Ambiental.

Sucedendo a Rio-92, em 1993 foi realizado o I Seminário Estadual de Educação Ambiental com o objetivo de conhecer e divulgar os trabalhos realizados em Educação Ambiental no estado de Mato Grosso do Sul, e, estrategicamente, integrar os educadores ambientais. Nesse evento, foram apresentados mais de 40 projetos em Educação Ambiental, com os mais diversos temas, dentre os quais destacaram-se: resíduos sólidos, tecnologia e meio ambiente, saúde pública, comunicação radiofônica, plantas medicinais, recursos hídricos, uso sustentável dos recursos naturais, entre outros. O encontro foi realizado com apoio do Fundo das Nações Unidas para a Infância - UNICEF/UNESCO, governo do estado de Mato Grosso do Sul, por meio da Secretaria de Estado do Meio Ambiente do Mato Grosso do Sul (SEMA-MS).

Os Seminários de Educação Ambiental para as Cidades Pantaneiras foram realizados durante quatro anos consecutivos entre 1999 e 2003 pela força de vontade de muitos educadores que fazem parte da história da Educação Ambiental no Mato Grosso do Sul. A mobilização por eles empreendida motivou a participação de suas instituições na formatação e efetivação desses espaços de diálogo, de planejamento, de troca de 
experiências e de vivificação da Educação Ambiental. Tais eventos aconteceram, respectivamente, nas cidades de Corumbá, Porto Murtinho, Aquidauana e também em Cuiabá, capital do Mato Grosso (MT), unindo educadores dos dois estados, MS e MT. Esses encontros de educadores serviram para ampliar o diálogo e a aproximação entre educadores do Brasil, Bolívia e Paraguai, fortalecendo uma rede de educadores em defesa do Pantanal e biomas adjacentes, a partir de reflexões e ações transfronteiriças. Os encontros apontavam para a perspectiva da Educação Ambiental Crítica, os quais culminaram na Fome Zero da Educação Ambiental, evento realizado em novembro de 2003 em Cuiabá-MT, com apoio da Rede Brasileira de Educação Ambiental-REBEA, Rede Mato-grossense de Educação Ambiental-REMTEA, Rede Aguapé Pantanal, ong MUPAN e Comissão da Carta da Terra.

Cumpre ressaltar que 1999 foi o ano da publicação da Política Nacional de Educação Ambiental - PNEA (Lei 9.795/99) e o Brasil já se tornara signatário da Convenção sobre Diversidade Biológica - CDB, estabelecida durante a Conferência das Nações Unidas sobre Meio Ambiente e Desenvolvimento, Rio/Eco-92. O Tratado de Educação Ambiental para Sociedades Sustentáveis e Responsabilidade Global, assim como a Carta da Terra, que se tornaram instrumentos para fundamentar as ações de Educação Ambiental, também já estavam em curso e se tornaram importantes documentos direcionadores da Educação Ambiental no Brasil, na luta por justiça social e ambiental.

Em 2012 é realizado pelo Instituto de Meio Ambiente do Mato Grosso do Sul (IMASUL) e parceiros, o I Fórum de Educação Ambiental de Mato Grosso do Sul com o objetivo de promover a interlocução de agentes para a consolidação de instrumentos e políticas voltadas para a Educação Ambiental no MS. Juntamente com o Fórum foi realizada uma das oficinas de construção da Política Estadual de Educação Ambiental do MS.

Apesar de 2019 ter sido marcado por uma política de governo em âmbito federal ameaçadora à PNEA a partir da extinção do Órgão Gestor e de seu Comitê Assessor, o MS sediou a Oficina do Centro-Oeste de Formação de Formadores em Monitoramento e Avaliação de Projetos e Políticas Públicas de EA. O evento reuniu educadores ambientais da região Centro-Oeste para capacitação sobre monitoramento e avaliação de políticas públicas de Educação Ambiental e contribuição ao banco de dados especializado sobre os indicadores de Educação Ambiental.

A essência da oficina no MS, assim como em outros estados, foi participativa, plural, e, conforme orientações de Raymundo et al. (2018), foi apresentada a construção dos indicadores de políticas públicas de EA, sendo o Tratado de Educação Ambiental para Sociedades Sustentáveis e Responsabilidade Global o alicerce para as políticas públicas em todo o Brasil. A oficina, também realizada em outras regiões brasileiras em 2019, pela Articulação Nacional de Políticas Públicas de Educação Ambiental (ANPPEA), constituiu-se em marco histórico de resistência e de luta dos educadores ambientais no Brasil.

Revbea, São Paulo, v.16, № 1: 493-507, 2021. 


\section{Obras literárias e publicações relacionadas à Educação Ambiental no Mato Grosso do Sul}

Em relação a publicações técnicas e pedagógicas na área de Educação Ambiental, os primeiros registros constam do Manual de Educação Ambiental e Conservação do Solo e Água (MELLO, 1982), elaborado pela parceria entre a Secretaria Estadual de Educação e o Ministério da Agricultura, com destino à Educação Ambiental Formal.

Como proposta ao público geral, em 2001 foi publicado o livro com textos para peças teatrais e atividades lúdicas "Interpretando a natureza subsídios para Educação Ambiental" (MAMEDE, 2001), com nova edição em 2003. No mesmo ano o livro "A poesia animal" traz a arte na forma de poesias como instrumento de sensibilização ambiental (SOUZA; OLÍVIO, 2003).

Já em 2006 é lançada a publicação intitulada "Educação Ambiental: gotas de saber" (VARGAS et al., 2006), que reúne artigos técnicos e científicos de vários educadores ambientais do estado com proposta de contribuição ao campo da pesquisa científica e de inspiração a novos projetos. Destacam-se, ainda, outras publicações como o livro "Pé na água: uma abordagem transfronteiriça da Bacia do Apa" (BROCH et al., 2008) e as edições das revistas da Rede Aguapé. Essas obras literárias são alguns dos indicadores dos caminhos da Educação Ambiental percorridos no estado e suas identidades.

\section{Redes de Educação Ambiental no Mato Grosso do Sul}

Em Mato Grosso do Sul atuam três redes de Educação Ambiental que integram a malha da Rede Brasileira de Educação Ambiental (REBEA), quais sejam: Rede Aguapé Pantanal, criada em 2001 com apoio do FNMA (Fundo Nacional de Meio Ambiente); Rede de Educação Ambiental do Cerrado (REACERRADO), da qual também participam outros estados do bioma Cerrado, criada em 2004 durante o Congresso de Educação Ambiental do Cerrado ocorrido em Quirinópolis-GO; e Rede de Educação Ambiental do Mato Grosso do Sul (REAMS), criada em 2008 durante o projeto "Educação Ambiental e Participação Comunitária" realizado pelo IMASUL e parceiros, com apoio do GEF Rio Formoso.

As redes são nós (elos) essenciais para o fortalecimento e estruturação de políticas públicas de Educação Ambiental. São modelos de organização que asseguram, de forma mais efetiva e horizontalizada, a participação comunitária nos processos decisórios e nas ações socioambientais, contribuindo na construção de territórios mais sustentáveis.

O Programa de educomunicação radiofônica Fala Cerrado foi uma das iniciativas de educadores ambientais das redes de EA presentes no MS. O programa foi idealizado por educadores ambientais que integram a REAMS e a REACERRADO que atuaram no Projeto Corredores de Biodiversidade 
Cerrado-Pantanal, núcleo Emas-Taquari. O Fala Cerrado nasceu como veículo de rede de educação e informação ambiental (RESENDE et al., 2007). Outras iniciativas radiofônicas como Boca da Mata e Prosa Pantaneira também estiveram presentes no MS com educadores ambientais do estado que atuaram na Rede Aguapé Pantanal.

Integrantes das Redes de EA do MS participaram ativamente na mobilização e organização dos pré-fóruns de EA (eventos que antecedem os Fóruns Brasileiros de Educação Ambiental), da construção de políticas públicas em nível federal como a ENCEA - Estratégia Nacional de Comunicação e Educação Ambiental no Âmbito do Sistema Nacional de Unidade de Conservação (2008 a 2010), bem como na revisão do Programa Nacional de Educação Ambiental - ProNEA e na organização do Comitê pró Rio+20 e Cúpula dos Povos, em 2012.

Educadores Ambientais da REACERRADO e da REAMS participaram do bonde Sul-mato-grossense do Bicicletada Nacional para Rio+20 e Cúpula dos Povos. O Bicicletada Nacional consistiu de um evento de equipes de ciclistas e cicloturistas partindo de várias regiões do Brasil rumo à Rio+20 e Cúpula dos Povos como forma de discutir mobilidade urbana sustentável e demonstrar que é possível a utilização da bicicleta como meio de transporte menos poluente para distintos percursos. Além disso, constituiu em estratégia criativa para disseminação da Carta da Terra e do Tratado de Educação Ambiental para Sociedades Sustentáveis e Responsabilidade Global. Houve também intervenções de arte-educação, diálogos sobre cidadania, participação social ativa e a necessidade de modelos mais sustentáveis de arquitetura e urbanismo que ofereçam mobilidade e qualidade de vida.

Educadores ambientais das três redes de EA do MS integram também a Comissão Interinstitucional de Educação Ambiental do Mato Grosso do Sul e tem contribuído na construção de políticas públicas locais e no fortalecimento da Educação Ambiental pelo estado de MS.

\section{Educação Ambiental no contexto escolar em Mato Grosso do Sul}

Especificamente, no que tange à Educação Ambiental Formal, destacase a participação de crianças e adolescentes das escolas sul-mato-grossenses nas cinco edições das Conferências Estaduais Infantojuvenis pelo Meio Ambiente nos anos de 2003, 2006, 2009, 2013 e 2018. As Conferências Estaduais promoveram a socialização dos diálogos ocorridos nas Conferências Escolares e projetaram novas ações a serem aprimoradas nas Conferências Nacionais. Cabe mencionar que no ano de 2010 ocorreu a única edição da Conferência Internacional Infantojuvenil (CONFIT), sob o tema "Vamos Cuidar do Planeta" e contou com a participação de uma delegada de Mato Grosso do Sul que, junto aos demais delegados e delegadas, escreveram cartas com responsabilidades direcionadas aos Ministros de Educação e de Meio Ambiente dos países participantes. 
A partir desse ano, deu-se início um forte movimento na Educação Ambiental Formal para o desenvolvimento de ações que aglutinem princípios da sustentabilidade socioambiental e das escolas sustentáveis. Como referência, foi lançado o Processo Formativo Escolas Sustentáveis e ComVida, e a UFMS responsabilizou-se por cursistas dos estados de Alagoas, Distrito Federal, Mato Grosso do Sul, Rio Grande do Norte e Santa Catarina. Foram "38 escolas participantes, perfazendo um total de 380 pessoas ligadas à comunidade escolar, dos quais, 245 cursistas foram selecionados a partir de demanda social' (WIZIACK et al., 2013, p. 4).

Assim, em 2012, as preocupações acerca da Educação Ambiental nas instituições de ensino foram materializadas nas Diretrizes Curriculares Nacionais para a Educação Ambiental (DCNEA) sob a Resolução CNE/CP no 02 de 15 de junho de 2012.

De acordo com as DCNEA, um dos objetivos da Educação Ambiental é o "estímulo à constituição de instituições de ensino como espaços educadores sustentáveis, integrando proposta curricular, gestão democrática, edificações, tornando-as referências de sustentabilidade socioambiental' (BRASIL, 2013, p. 560).

Decorrente desta iniciativa, a edição de 2013 das Conferências Infantojuvenis pelo Meio Ambiente adotou o tema "Vamos Cuidar do Brasil com Escolas Sustentáveis". Para subsidiar as escolas foi proposto um caderno temático que apresentou possibilidades de ações escolares nas dimensões do currículo, da gestão democrática e das edificações, corroborando assim, os pressupostos das DCNEA.

Ainda no ano de 2013, a Conferência Estadual Infantojuvenil pelo Meio Ambiente contou com a presença de 84 escolas, o que permite dimensionar que estiveram presentes 166 estudantes e 84 professores durante a Conferência que discutiu o tema "escolas sustentáveis".

No primeiro semestre de 2014, foi lançado o Programa Nacional Escolas Sustentáveis (PNES) que teve como objetivo principal a contribuição para a melhoria da qualidade da educação básica e o apoio à transição das escolas para constituírem-se em espaços educadores sustentáveis (BRASIL, 2014). Para isso, o PNES trouxe quatro componentes, a saber: currículo na escola sustentável; gestão democrática para a sustentabilidade; espaço escolar e sustentabilidade; e relações escola-comunidade.

Dentre as ações veiculadas pelo PNES em Mato Grosso do Sul, ilustramos a oferta pela Universidade Federal de Mato Grosso do Sul da pósgraduação lato sensu em Educação Ambiental e Espaços Educadores Sustentáveis com a efetivação de duas edições, 2013/2014 e 2015/2016, com um total de 550 vagas; do curso de extensão Educação Ambiental e Escolas Sustentáveis e Com-Vida; do financiamento via Programa Dinheiro Direto na Escola, PDDE Escola Sustentável; e a V Conferência Infantojuvenil pelo Meio Ambiente. 
Em Mato Grosso do Sul, a edição de 2014 do PDDE Escola Sustentável contemplou com recursos financeiros para atividades de Educação Ambiental com o total de 160 escolas públicas e a última Conferência Estadual, em 2018, teve 150 participantes, entre estudantes e professores. Considerando os colaboradores, membros da CIEA e membros do Coletivo Jovem de Meio Ambiente, o contingente atingiu cerca de 200 pessoas.

Ainda em 2017, impulsionada pelas discussões nacionais, a Secretaria de Estado de Educação de Mato Grosso do Sul estabeleceu para as escolas da rede estadual a Resolução SED no 3.322, de 13 de setembro de 2017, que dispõe sobre a oferta da Educação Ambiental. De acordo com esta resolução, a EA "é tema integrante do currículo, essencial e permanente da educação formal, e deve estar presente, de forma articulada aos conhecimentos adquiridos pelos estudantes, em todas as etapas e demais modalidades de ensino, e inserida no Projeto Político Pedagógico" (MATO GROSSO DO SUL, 2017, p. 6).

Note-se que o estado de Mato Grosso do Sul traz em seu histórico o engajamento de educadores ambientais em processos de formação para transição de territórios sustentáveis, sendo que a Educação Ambiental Formal teve um avanço significativo no recorte temporal de 2003 a 2018, devido aos movimentos dos educadores ambientais de Mato Grosso do Sul e dos Programas Federais, mobilização do Coletivo Jovem de Meio Ambiente, diversas atividades educativas formais, acerca da sustentabilidade socioambiental e da proposição dos espaços educadores sustentáveis.

Ademais, a Universidade Federal de Mato Grosso do Sul (UFMS) efetivou o programa de pós-graduação lato sensu "Educação Ambiental e Espaços Educadores Sustentáveis" (2012) e, mais tarde, o programa stricto sensu em Ensino de Ciências, em nível de mestrado e doutorado contemplado com a linha de pesquisa em Educação Ambiental, que dispõe em seu banco de dados inúmeras pesquisas de Educação Ambiental formal e não formal. Outras instituições de ensino superior que possuem programas de pós-graduação de caráter interdisciplinar também contribuem com pesquisas em Educação Ambiental como o Programa de Pós-graduação em Meio Ambiente e Desenvolvimento Regional da Universidade para o Desenvolvimento do Estado e Região do Pantanal - UNIDERP e o Programa de Pós-graduação em Desenvolvimento Local da Universidade Católica - UCDB.

\section{Desafios para consolidação das políticas públicas de Educação Ambiental no Mato Grosso do Sul}

Desde a criação do estado de Mato Grosso do Sul, educadores trabalharam para a implantação de uma Política Estadual de Educação Ambiental (PEEA-MS), mas só no século 21 é que teve seu escopo elaborado, entre os anos de 2003 e 2004. Posteriormente, foram realizadas oficinas de construção da PEEA-MS, de forma participativa, por meio do projeto "Educação Ambiental Itinerante", empreendido pelo IMASUL em diversos municípios do 
estado. As consultas públicas foram concluídas com a "Oficina de Construção da Política de Educação Ambiental" durante o I Fórum de Educação Ambiental de Mato Grosso do Sul ocorrido em Campo Grande, em 2012. Com base nas contribuições das consultas públicas, os integrantes da Comissão Interinstitucional de Educação Ambiental (CIEA-MS) dedicaram-se à consolidação do texto da Minuta da Política, sendo finalizada e entregue ao governo do estado, em 2014, com 40 artigos.

Em 2017 integrantes do governo, ajustaram o documento reduzindo os 40 artigos da Minuta de lei para 19 e apresentaram à assembleia legislativa o "Projeto de Lei da Política Estadual de Educação Ambiental de Mato Grosso do Sul" (PEEA-MS), de forma mutilada e sem pactuar com a CIEA. Com isso, a CIEA constituiu um grupo de trabalho (GT) em defesa da Política Estadual de Educação Ambiental que fosse o mais próximo do original, cujo texto havia sido construído de forma participativa e democrática entre os mais diversos atores. Os integrantes da CIEA, com intuito de sensibilizar os parlamentares estaduais e solicitar emendas à Minuta de Lei, realizaram uma mobilização junto aos mesmos, com apresentação do histórico da construção da política e solicitaram reunião pública para debater junto à sociedade a Política de Educação Ambiental necessária e atenta às demandas locais e suas singularidades em contínuo diálogo com as perspectivas globais.

Com a realização de reunião pública na Assembleia Legislativa, foram conquistadas algumas emendas sugeridas pela CIEA, tais como a valorização da cultura e dos saberes dos povos e comunidades tradicionais, bem como a valorização das bacias hidrográficas, biomas, ecossistemas, territórios e municípios do Mato Grosso do Sul. No entanto, outras ficaram ausentes, dentre as quais, a referente ao Fundo Estadual de Educação Ambiental, um dos importantes instrumentos para a efetivação e fortalecimento da Política de EA/MS. Dessa forma, Mato Grosso do Sul foi o último estado da federação brasileira a instituir sua Política Estadual de Educação Ambiental.

A Política Estadual de Educação Ambiental do Mato Grosso do Sul (Lei $5.287 / 2018$ de 13 dezembro de 2018) se concretizou com três instrumentos para a EA no estado, sendo eles: o Sistema Estadual de Informação em Educação Ambiental (SisEA-MS), o Programa Estadual de Educação Ambiental (ProEEA-MS) e a Comissão Interinstitucional de Educação Ambiental (CIEA-MS). Cabe ressaltar que o SisEA e a CIEA já existiam antes mesmo da aprovação da PEEA-MS e com a aprovação da lei esses instrumentos foram incorporados, normatizados e amparados legalmente.

O SisEA constitui um banco de dados acessível aos cidadãos com informações de ações e projetos em Educação Ambiental desenvolvidos no território do Mato Grosso do Sul. Qualquer cidadão/ã pode acessar e observar os projetos cadastrados e, principalmente, órgãos públicos, empresas que atuam com gestão ambiental e aquelas que necessitam apresentar programa de Educação Ambiental para licenciamento ambiental de empreendimentos 
consultam o SisEA com frequência a fim de acompanhar as ações de Educação Ambiental e nelas inspirar as suas próprias.

A CIEA-MS foi criada pelo Decreto no 9.939 , de 05 de junho de 2000 e reformulada pelo Decreto no 12.741, de 07 de abril de 2009. Congrega representantes de instituições públicas, privadas e do terceiro setor com intuito de estabelecer as bases da Educação Ambiental no Estado como uma oportunidade para a transformação e ações socioambientais. A CIEA/MS possui caráter consultivo e tem como objetivo promover o diálogo, 0 acompanhamento e a avaliação da Política e do Programa Estadual de Educação Ambiental. A CIEA desempenhou papel fundamental no processo de construção da Política Estadual de Educação Ambiental (PEEA-MS), porém, ao final, dado o seu caráter consultivo de decisão, prevaleceu a proposta do governo de conclusão da minuta de lei da Política Estadual à revelia dos anseios dos educadores ambientais e do que havia sido construído de forma democrática em âmbito estadual.

O ProEEA/MS concluído e publicado três meses antes da instituição da PEEA/MS tem em sua essência os princípios, objetivos, diretrizes e linhas de ação, concretizando-se como importante instrumento de gestão para 0 desenvolvimento de ações de Educação Ambiental, atendendo às peculiaridades socioambientais do estado do Mato Grosso do Sul (MATO GROSSO DO SUL, 2018). Trata-se de um documento importante capaz de direcionar as propostas de Educação Ambiental para que sejam interdisciplinares, inclusivas e transformadoras da realidade socioambiental.

Entre os desafios para a consolidação de Políticas Públicas em Educação Ambiental, estão a busca de alternativas de conciliar a conservação ambiental, os interesses do capital e do agronegócio, este insistentemente tem sido visto como principal base econômica do Mato Grosso do Sul. Se de um lado há os interesses da coletividade por justiça social e ambiental, proteção dos biomas, respeito aos povos tradicionais, ribeirinhos, quilombolas e indígenas, por outro, do empresariado que conta com apoio dos governos no cumprimento da agenda do agronegócio e das formas tradicionais de produção capitalista, excludente e ameaçadoras à sociobiodiversidade. Sorrentino et al. (2005) alertam sobre a necessidade de transformação social pela Educação Ambiental visando a superação das injustiças ambientais, da desigualdade social, da apropriação capitalista e funcionalista da natureza e da própria humanidade.

Como em outros lugares, a EA no MS historicamente se construiu diante das preocupações com os habitats naturais e com a biodiversidade com forte visão naturalista da Educação Ambiental. Temas como tratamento e disposição de resíduos sólidos, plantio e recomposição vegetal, combate à poluição das águas e proteção dos recursos hídricos são recorrentes nas campanhas, projetos e programas de Educação Ambiental.

Ações de Educação Ambiental pontuais marcam a história, às vezes 
caça de jacarés, as ameaças da instalação de usinas sucroalcooleiras no Pantanal e, o próprio Pantanal, tem sido alvo de discussões, debates e estratégias de proteção para salvaguardar a maior planície inundável do planeta. Admite-se que outros biomas do estado, infelizmente, não têm recebido a mesma visibilidade e protagonismo em ações e campanhas de Educação Ambiental. Ações isoladas têm sido realizadas em relação ao Cerrado, Mata Atlântica e Chaco, biomas distribuídos no MS. Ainda assim, buscam gerar reflexão e transformação de posturas, e têm auferido bons resultados.

Mas, o enraizamento engendra-se, possivelmente, por dois caminhos: por ações dos órgãos governamentais de meio ambiente e de educação, os quais possuem suas próprias ações e metodologias para o desenvolvimento da Educação Ambiental, visto se tratar de uma pauta imanente a esses órgãos. Outro contingente de atores é formado por membros da sociedade civil, como ONGs, coletivos, colegiados e movimentos sociais que percorrem vias paralelas e convergentes às dos órgãos governamentais. Em ambos os casos, muitas ações começam, todavia não têm continuidade, seja pela interrupção de gestão administrativa, seja porque o objetivo era justamente uma campanha ou ação pontual.

De fato, a implementação das políticas esbarra nos conflitos entre os diferentes níveis de governos e principalmente entre os distintos atores envolvidos (FERREIRA, 2012). Apesar de muitas vezes, por força de dispositivos legais, a EA no licenciamento ambiental também tem contribuído para a sensibilização pública de cuidado com o meio. Acadêmicos e pesquisadores, cujos estudos e publicações técnicas dão suporte às ações devem ser lembrados e valorizados. Mesmo que possa haver autores não diretamente engajados em ações continuadas de EA, estudos técnicocientíficos subsidiam e oferecem oportunidade de conhecimento e caminhos para solução de problemas, leitura do mundo, reflexões e alternativas para construção de territórios sustentáveis.

Além disso, outros questionamentos devem orientar pautas formativas em Educação Ambiental, sobretudo àqueles que buscam romper com propostas educativas estritamente biologizantes e reducionistas. Por isso, defendemos que as atividades nas instituições de ensino sejam pautadas na perspectiva da Educação Ambiental Transformadora, por entender que "busca compreender e teorizar na atividade humana, ampliar a consciência e revolucionar a totalidade que constituímos e pela qual somos constituídos" (LOUREIRO, 2003, p. 44).

Manter a mobilização dos coletivos tem sido desafio primário, mas necessário no momento atual e conjuntura política. Resistir é preciso. Planejar iniciativas, projetos e programas necessita do olhar mais sistêmico para o desenvolvimento da EA transformadora (LOUREIRO, 2003), a qual está alinhada à Educação Ambiental Crítica. Depois da fase inicial, é necessário priorizar uma EA plural, que dialogue e priorize aspectos sociais do meio. 
Ambiente natural não está dissociado da sociedade, não cabendo a dicotomia sociedade-natureza. Desenvolver empatia pelo ser humano e não humano, buscar métodos e ações para reduzir desigualdades sociais, que respeitem direitos de cidadania também são processos da Educação Ambiental. Por isso, é preciso que as ações caminhem para a proposição e implantação de políticas públicas. Apesar da morosidade e pontos divergentes das propostas delineadas, é direito dos cidadãos desfrutar de políticas públicas que busquem soluções aos problemas socioambientais e resguardem a vida respeitosa em sociedade. Além disso, é preciso oportunizar a participação plural e ativa nos debates que envolvam educação e cidadania, reiterando que a riqueza e força de uma nação residem na diversidade.

Outro aspecto importante é a articulação entre Estado e sociedade civil na promoção da cidadania, por meio do revigoramento das redes que se instrumentalizam a fim de promover ações coletivas e monitorar as ações públicas voltadas para as questões socioambientais (FERREIRA, 2012). Além disso, as secretarias estaduais de governo de educação e de meio ambiente precisam trabalhar em sintonia com ações conjuntas, mesmo que uma seja encarregada de políticas educacionais formais e não formais.

Neste caso, reafirmamos algumas ações existentes que podem ser revigoradas, tais como: Coletivo Jovem pelo Meio Ambiente (CJ); Coletivos Educadores; Salas Verdes; Comissão de Meio Ambiente e Qualidade de Vida na Escola (Com-Vida); Redes de Educação Ambiental; Comissão Interinstitucional de Educação Ambiental (CIEA). Todos estes coletivos, sejam com participação de órgãos institucionais ou não, promovem o protagonismo dos cidadãos, a dialogicidade entre esferas públicas, saberes plurais, integrados e conhecimentos intergeracionais.

No tocante ao firmamento de Políticas Públicas há que se estabelecer monitoramento e avaliação das estratégias e ações previstas no Programa Estadual de Educação Ambiental, tanto pela Secretaria de Estado de Meio Ambiente e de Educação.

Desse modo, devemos superar metodologias e estratégias avaliativas que não sejam inclusivas e dialógicas e romper a supremacia do conhecimento científico em detrimento dos saberes tradicionais, havendo necessidade de integração de saberes. Valorizar a ciência sem esquecer dos saberes da comunidade é o caminho para a sustentabilidade dos territórios. Vivenciar a temática socioambiental é preciso, numa perspectiva crítica, e não somente descrevê-la no Projeto Político Pedagógico da escola ou mesmo em legislações verticalizadas e colocadas para a sociedade. Afinal, a chave de superação dessas problemáticas é que o ciclo das políticas públicas ambientais seja um processo realmente democrático com a população e não para a população.

Neste sentido, ações como: participação em grupos de estudo e pesquisas; fomento ao ingresso de professores da educação básica em Programas de pós-graduação stricto sensu; e Programas de Formação 
Continuada em serviço podem contribuir para práticas educativas mais participativas, abrangentes, democráticas e inclusivas.

\section{Conclusões}

O estado de Mato Grosso do Sul é marcado historicamente pela contradição entre 0 desenvolvimento econômico $e$ as condições socioambientais. Enquanto as forças do agronegócio e da política neoliberal avançam no discurso da melhoria desenvolvimentista do estado, diversos educadores ambientais lutam por condições dignas aos povos tradicionais, aos saberes locais e à harmonia da coletividade.

Evidenciamos as diversas atividades, sejam no campo da EA formal ou não formal, que comprovam o constante engajamento e ritmo dos educadores ambientais de Mato Grosso do Sul em uma luta contra-hegemônica, sobrepondo as humanidades ao capitalismo. Tendo em conta que a Educação Ambiental visa à superação das injustiças ambientais, da desigualdade social, da apropriação capitalista e funcionalista da natureza e da própria humanidade (SORRENTINO, 2005).

Destacamos o grande esforço da CIEA/MS em divulgar, promover, dialogar, pesquisar e documentar uma proposta de Política Estadual de Educação Ambiental que revelasse as necessidades e os anseios dos povos de MS. Esta, não teve o desfecho desejado, haja vista a exclusão de itens importantes do texto por parte do governo estadual. No entanto, mesmo com a Política Estadual alterada sem consulta qualificada à CIEA foi possível lançar o Programa Estadual de Educação Ambiental. Este pode oportunizar novos diálogos entre a CIEA, os cidadãos de Mato Grosso do Sul e o governo estadual para futuras políticas públicas de Educação Ambiental.

Mas as políticas estaduais não se fazem isoladamente e sim conectadas às nacionais. Por isso, as políticas institucionais e governamentais, especialmente em âmbito federal, são essenciais para emanar apoio institucional, financeiro e motivacional para estados e municípios. Os órgãos gestores da Política de Educação Ambiental, Ministério do Meio Ambiente e Ministério da Educação, são estruturantes e precisam estar fortalecidos para darem suporte aos entes federativos. Sendo assim, qualquer força de desmonte e de esfacelamento dessas instâncias de governança precisa ser veementemente refutada e combatida pela união dos educadores ambientais de todos os estados da federação brasileira.

\section{Agradecimentos}

Agradecemos o apoio do Instituto Mamede de Pesquisa Ambiental e Ecoturismo e da Universidade Federal de Mato Grosso do Sul - UFMS/MEC, Brasil. 


\section{Referências}

ALVES, G.L. Mato Grosso do Sul: o universal e o singular. Campo Grande: Uniderp, 2003. 101p.

BRASIL. Ministério do Meio Ambiente, dos Recursos Hídricos e da Amazônia Legal; Secretaria de Coordenação dos Assuntos de Meio Ambiente; Programa Nacional do Meio Ambiente; Projeto Pantanal. Plano de Conservação da Bacia do Alto Paraguai - PCBAP, 1997.

BRASIL. Ministério da Educação. Programa Nacional Escolas Sustentáveis versão preliminar. Disponível em: <https://docplayer.com.br/19725938Programa-nacional-escolas-sustentaveis.html>. Acesso em: 07 ago. 2019.

BRASIL. Ministério da Educação. Diretrizes Curriculares Nacionais Gerais da Educação Básica / Ministério da Educação. Secretaria de Educação Básica. Diretoria de Currículos e Educação Integral. Brasília: MEC, SEB, DICEI, 2013.

BROCH, S.O.; MEDEIROS, Y.; SOUZA, P.R. Pé na água: uma abordagem transfronteiriça da bacia do Apa - Campo Grande: UFMS, 2008. 128p.

FERREIRA, L.C. A questão ambiental: sustentabilidade e políticas públicas no Brasil. São Paulo: Boitempo, 2012. 154 p.

LOUREIRO, C.F.B. Premissas teóricas para uma Educação Ambiental transformadora. Revista Ambiente e Educação, Rio Grande, 8: 37-54, 2003.

MAMEDE, S.B. Interpretando a natureza: subsídios para a Educação Ambiental. Campo Grande: Campo Grande. Editora Oeste, 2001. 158p.

MAMEDE, S.B. Interpretando a natureza: subsídios para a Educação Ambiental. Campo Grande: UNIDERP, 2003. 123p.

MATO GROSSO DO SUL. Lei n. 5.287, de 13 de dezembro de 2018. Dispõe sobre a Política Estadual de Educação Ambiental de Mato Grosso do Sul (PEEA/MS). Instituto de Meio Ambiente de Mato Grosso do Sul (IMASUL). Campo Grande, MS. Disponível em: <http://www.imasul.ms.gov.br>. Acesso em: 20 jul. 2019.

MATO GROSSO DO SUL. Programa Estadual de Educação Ambiental de Mato Grosso do Sul (ProEEA/MS). IMASUL/WWF: Campo Grande. Disponível em: <http://www.imasul.ms.gov.br/wp-content/uploads/2018/09/PROGRAMAESTADUAL-DE-EDUCAC\%CC\%A7A\%CC\%830-AMBIENTALMS-2018.pdf>. Acesso em: 15 mai. 2019.

MATO GROSSO DO SUL. Resolução SED n. 3322, de 17 de setembro de 2017 que dispõe sobre a Educação Ambiental na rede estadual de ensino. Diário Oficial n. 9494 de 15 de setembro de 2017. 
RAYMUNDO, M.H.A.; BRANCO, E.A.; BIASOLI, S. Indicadores de Políticas Públicas de Educação Ambiental: construção à luz do Tratado de Educação Ambiental para sociedades sustentáveis e responsabilidade global e da Política Nacional de Educação Ambiental. Cadernos de Pesquisa: Pensamento Educacional, número especial, p. 337-358, 2018.

RESENDE, I.S.; MAMEDE, S.B; BENITES, M. Programa de rádio Fala Cerrado como veículo de rede de educação e informação ambiental. São Paulo. Revista Brasileira de Educação Ambiental, v. 1, n. 2, p.115-119, 2007.

SORRENTINO, M.; TRAJBER, R.; MENDONÇA, P.; FERRARO, L. Educação Ambiental como política pública: São Paulo. Educação e pesquisa, v. 31, n. 2, p. 285-299, 2005.

SOUZA, P.R.; OLÍVIO, S. Poesia Animal. Campo Grande: UFMS, 2003. 150p.

WIZIACK, S.R.C., VARGAS, I.A., ZANON, A.M. Programa Escolas Sustentáveis: reflexões para a formação de educadores ambientais no Brasil. Anais eletrônicos. VII EPEA - Encontro Pesquisa em Educação Ambiental Rio Claro - SP, 07 a 10 de Julho de 2013 Realização: Unesp campus Rio Claro e campus Botucatu, USP Ribeirão Preto e UFSCar. Disponível em: <http://www.epea.tmp.br/epea2013 anais/pdfs/plenary/0136-1.pdf> Acesso em 07 ago 2019. 